\title{
Controlled Study of a New Inhalant in Asthma and Bronchitis
}

\author{
A. H. EL-SHABOURY,* M.B., D.C.H.
}

Brit. med. F., 1964, 2, 1037-1040

Isoprenaline inhalant is effective in relieving minor attacks of asthma, but palpitations, dizziness, and headaches can be troublesome in some cases. An inhaler as efficient as isoprenaline, and without such side-effects, is desirable. A new sympathomimetic amine, isoetharine, was found to be as effective as $1 \%$ isoprenaline without producing systemic upsets (Herschfus et al., 1951).

Isoetharine (1-[3,4-dihydroxyphenyl]-2-isopropylamino-1butanol hydrochloride) is a derivative of isoprenaline and ethylnoradrenaline and has the following formula:<smiles>CCC(NC(C)C)C(C)C1CCC(O)CC1</smiles>

It is an effective antagonist of histamine-induced bronchoconstriction in the guinea-pig, and its action is enhanced by the addition of the antihistamine drug thenyldiamine hyrochloride (Lands et al., 1958). It is readily absorbed along the mucous membranes of the respiratory and gastro-intestinal tracts of the dog (Lands, 1962).

Bronchilator is a triple-drug aerosol containing isoetharine, phenylephrine (a vasoconstrictor and mild bronchodilator), and thenyldiamine (an antihistamine). American workers (Spielman, 1961 ; Siegel, 1962 ; Goldfarb and Romanoff, 1962) have reported the value of the triple aerosol in bronchial asthma, and its freedom from side-effects even in hypertensive patients. The aim of this work is to compare objectively the degree and duration of effect of Bronchilator ${ }^{1}$ with that of isoprenaline ${ }^{2}$ and a placebo aerosol ${ }^{3}$ in a double-blind controlled study.

\section{Material}

Patients attending the asthma clinic who had low records of lung-function tests (F.E.V. $\cdot_{1}$ of 1,000 or below over the past two to three years) were selected, and asked to discontinue all tablets for a period of 24 hours prior to the day of study. If, however, they became distressed their usual inhaler could be used and the time noted. The patients co-operated, and on arrival at the unit all were wheezy and most felt tightness in the chest.

The age and sex distribution of the 60 patients who took part in this trial are shown in Table I. Thirty-five had asthma and 25 bronchitis. Of the 44 females, 31 (70\%) were asthmatics ; of the 16 males, only $4(25 \%)$ had asthma. Seven females and one male had hypertension, and three of these also had coronary artery disease.

Certain criteria (Higgins, 1957 ; Williams, 1961 ; Scadding, 1963) were followed when the diagnosis of either asthma or

\footnotetext{
* Medical Registrar, St. David's Hospital, Cardiff.

1 Bronchilator aerosol contains isoetharine $0.6 \%$, phenylephrine hydrochloride $0.125 \%$, and thenyldiamine hydrochloride $0.05 \%$. Each metered dose delivers isoetharine $350 \mu \mathrm{g}$., phenylephrine $70 \mu \mathrm{g}$., and thenyldiamine $30 \mu \mathrm{g}$.

Isoprenaline aerosol contains isoprenaline hydrochloride $0.25 \% \mathrm{w} / \mathrm{w}$. Each metered dose delivers $125 \mu \mathrm{g}$. of isoprenaline hydrochloride.

- Placebo aerosol contains $64 \% \mathrm{w} / \mathrm{w}$ propellant, $35.8 \%$ alcohol, preservative, saccharin, and essential oils as in both active inhalers.
}

bronchitis was made. A patient was considered to have asthma from the typical history of paroxysmal attacks of dyspnoea and wheezing, often occurring at night, the marked fluctuations in lung-function-test measurements as recorded on previous attendances at the clinic, and the great improvement in these tests after steroid therapy. A patient attending the clinic was considered to have bronchitis from a history of productive cough (for at least three consecutive months in the year), troublesome particularly in the morning, and at least one chest illness characterized by increased cough and sputum during the past three years. The levels of F.E.V.. measurements recorded

TABLE I.-Age and Sex Distribution of 60 Patients

\begin{tabular}{|c|c|c|c|c|c|c|c|c|c|}
\hline & \multirow{2}{*}{\multicolumn{2}{|c|}{$\begin{array}{l}\text { Duration } \\
\text { of Illness }\end{array}$}} & \multicolumn{6}{|c|}{ Age-groups } & \multirow{2}{*}{ Total } \\
\hline & & & $21-30$ & $31-40$ & $|41-50|$ & $51-60$ & $60-70$ & $70+$ & \\
\hline \multirow[t]{2}{*}{ Men } & $\begin{array}{l}\ll 10 \text { years } \\
>10 \text { years }\end{array}$ & 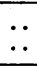 & $\overline{-}$ & $\overline{1}$ & $\begin{array}{l}2 \\
1\end{array}$ & $\begin{array}{l}4 \\
2\end{array}$ & $\begin{array}{l}3 \\
3\end{array}$ & $\overline{-}$ & $\begin{array}{l}9 \\
7 \\
\end{array}$ \\
\hline & Total & .. & - & 1 & 3 & 6 & 6 & - & 16 \\
\hline \multirow{2}{*}{ Women } & $\begin{array}{l}\ll 10 \text { years } \\
>10 \text { years }\end{array}$ & $\therefore$ & $\overline{2}$ & $\begin{array}{l}1 \\
2\end{array}$ & $\begin{array}{r}2 \\
11\end{array}$ & $\begin{array}{l}3 \\
8\end{array}$ & $\begin{array}{l}5 \\
8\end{array}$ & $\overline{2}$ & $\begin{array}{l}11 \\
33\end{array}$ \\
\hline & Total & . & 2 & 3 & 13 & 11 & 13 & 2 & 44 \\
\hline \multicolumn{2}{|c|}{ Total (both sexes) } & $\cdots$ & 2 & 4 & 16 & 17 & 19 & 2 & 60 \\
\hline
\end{tabular}

for each bronchitic patient over the past three years varied slightly (variation rarely more than $\pm 150 \mathrm{ml}$.) and no improvement in lung-function tests had occurred after steroid therapy.

\section{Methods}

The trial was carried out in two parts. Part I was designed to show the effect of the three treatments on the same patient, and Part II was to compare the effect and duration of Bronchilator and isoprenaline inhalants on two separate groups of patients. On arrival at the unit the patients rested for 10 minutes; the proper use of the inhalers was explained and any treatment taken during the previous 24 hours recorded. Measurements of the forced expiratory volume in the first second (F.E.V.. ), forced vital capacity (F.V.C.), and the peak flow rate (P.F.R.) were carried out by the chief technician, and the pulse and blood-pressure by me. The Gaensler-type spirometer modified by McKerrow et al. (1960) was used throughout and calibrated each morning. P.F.R. was measured by Wright's peak flow meter (Wright and McKerrow, 1959).

Part I.-The placebo, isoprenaline, and Bronchilator inhalers, identical in colour, shape, and taste, were labelled A, B, and C. Neither the patient nor the staff involved in the trial were aware of the key to the code during the trial. After initial control measurements of F.E.V..1, F.V.C., P.F.R., pulse, and blood-pressure, three inhalations from the first inhaler were administered. These measurements were then determined at 15 and 30 minutes. The process was then repeated with the other inhalers. Each of the 60 patients participated in six distinct trial sessions of one and a half hours each, four in one day and two during a half-day 24 hours later. Each session consisted of the three treatments, given in turn at half-hourly intervals. The order of the three treatments in each session was predetermined so that each session corresponded to one of the six possible orders in which these treatments could be administered (Table II). Twenty-eight patients began both the full-day and the half-day sessions at 9 a.m. The remaining 32 
began the first two sessions at 2 p.m. and the final four at 9 a.m. Patients were encouraged to do their best in every lungfunction test, and repeat measurements were taken whenever necessary. Any undesirable side-effects were noted.

\begin{tabular}{|c|c|c|c|}
\hline \multirow{2}{*}{$\begin{array}{l}\text { Session } \\
\text { Order }\end{array}$} & \multicolumn{3}{|c|}{ Treatment Order } \\
\hline & $1 \mathrm{st}$ & 2nd & $3 \mathrm{rd}$ \\
\hline $\begin{array}{l}1 \text { st } \\
\text { 2nd } \\
\text { 3rd } \\
4 \text { th } \\
5 \text { th } \\
6 \text { th }\end{array}$ & $\begin{array}{l}\text { Placebo } \\
\text { Isoprenaline } \\
\text { Bronchilator } \\
\text { Placebo } \\
\text { Isoprenaline } \\
\text { Bronchilator }\end{array}$ & $\begin{array}{l}\text { Isoprenaline } \\
\text { Bronchilator } \\
\text { Placebo } \\
\text { Bronchilator } \\
\text { Placebo } \\
\text { Isoprenaline }\end{array}$ & $\begin{array}{l}\text { Bronchilator } \\
\text { Placebo } \\
\text { Isoprenaline } \\
\text { Isoprenaline } \\
\text { Bronchilator } \\
\text { Placebo }\end{array}$ \\
\hline
\end{tabular}

Part II.-A member of the staff not involved in the trial now identified the placebo as code letter A. The staff conducting the trial still remained blind as regards the code for the two active preparations (B and $C$ ). Two separate groups were formed from the same 60 patients. These were matched on the basis of age, diagnosis, and levels of lung-function tests. Twenty-one patients were arbitrarily allocated to drug B and 23 similarly to drug C. After the initial control measurements, six inhalations of the placebo were administered and the measurements were repeated at 5 and 15 minutes. Six inhalations were then given of either aerosol B or C, and these measurements were again determined at 5 and 15 minutes and subsequently every 15 minutes up to 180 to 195 minutes. Previous therapy was restricted as in Part.I, and no other treatment was used during the test. All patients had an electrocardiogram before and after this part.

\section{Medication Prior to Test}

Part 1.-Patients had no treatment for at least 12 hours before the test on 104 out of 120 attendances. On six occasions the patient's usual inhaler was used three to seven hours previously, on nine occasions two hours, and once one and a half hours. Twenty-seven asthmatics were on long-term corticosteroids. The mean time period between the administration of cortiscosteroids and the beginning of the test was 16.7 hours, with a standard deviation of 4.9 hours.

Part II.-Sixteen out of 21 patients in the isoprenaline group and 21 out of 23 in the Bronchilator group had no treatment for at least 12 hours. One patient used his inhaler three-quarters of an hour before the test, two at two hours, one at six hours, one at nine and a half hours, and two at eleven and a half hours. The mean time periods between the last administration of steroids and the beginning of the test were 21 hours and $18 \frac{3}{4}$ hours for isoprenaline and Bronchilator groups respectively.

\section{Lung-function Tests}

\section{Results}

Part I.-Of 4,680 possible records of F.E.V. $\cdot_{1}$ and F.V.C., four are missing. The peak flow meter did not register a reading on 136 occasions involving 20 patients. The median for the number of missing values per patient was six. For the purpose of the statistical analysis, the missing values were interpolated. The data from asthmatics and bronchitics were analysed as one group. A patient's control readings in any one session were deducted from all three measurements in that session. Thus increases in lung-function-test performances after treatment were considered, with each patient acting as his own control. Table III shows the mean increases in lungfunction tests after the three treatments. The placebo resulted in the smallest increase for every test, and the differences between the active drugs and the placebo were significant at $1 \%$ level for all three tests. The mean increase after Bronchilator was higher than after isoprenaline. The differences were significant at $5 \%$ level for F.E.V. and at $1 \%$ level for F.V.C., but not significant for P.F.R. measurements. Patients differed significantly in the extent of their improvement after treatments, and 10 cases $(17 \%)$ improved more with isoprenaline than with Bronchilator. Analysis of lung-function-test improvements for each session showed that the order in which the treatments were given affected the results significantly. The third session had the highest mean improvements for all three tests (F.E.V. 216.8 ml., F.V.C. $365.6 \mathrm{ml}$., and P.F.R. 328 1., and the fifth session had also high means (F.E.V. $106.8 \mathrm{ml} .$, F.V.C. $310.7 \mathrm{ml}$., and P.F.R. 217 1.). The placebo was placed between the two active drugs in these two sessions (see Table II), and maximum drug and carry-over effects from the previous active drug are evident. The effect of both active drugs lasted more than the 30-minute interval allowed in this stage.

\begin{tabular}{|c|c|c|c|c|c|}
\hline & & $\begin{array}{l}\text { Placebo } \\
\text { (A) }\end{array}$ & $\begin{array}{l}\text { Isoprenaline } \\
\text { (B) }\end{array}$ & $\begin{array}{l}\text { Bronchilator } \\
\text { (C) }\end{array}$ & $\sqrt{\frac{\text { m.s. error }}{\text { (d.f.) }}}$ \\
\hline $\begin{array}{l}\text { F.E.V.1 } \\
\text { F.V.C. } \\
\text { P.F.R. }\end{array}$ & $\begin{array}{l}. \\
\therefore\end{array}$ & $\begin{array}{l}25.3 \\
65.8 \\
40.5\end{array}$ & $\begin{array}{l}119.5 \\
205.8 \\
194.0\end{array}$ & $\begin{array}{l}145 \cdot 0 \\
275.7 \\
200 \cdot 0\end{array}$ & $\begin{array}{l}87 \cdot 7(1,080) \\
131 \cdot 1(1,080) \\
408 \cdot 0(1,080)\end{array}$ \\
\hline
\end{tabular}

Part II.-Control readings for all three lung-function tests were deducted from all measurements as in Part I. The results were also used to check that no systematic difference existed between the isoprenaline and Bronchilator groups regarding their performance in the three tests. Figs. 1, 2, and 3 show the mean effect and duration of Bronchilator and isoprenaline on the three tests in asthmatics and bronchitics. It can be seen that Bronchilator curves remained above those of isoprenaline for at least two hours with the exception of the F.V.C. curve in bronchitics. Improvement in lung-function-tests after both active drugs was much greater in asthmatics than in bronchitics; the difference in F.E.V. improvements was highly significant $(P \ll 0.001)$. Mean improvements in all three tests were greater after Bronchilator than isoprenaline; the differences in F.E.V. ${ }_{1}$ were significant at $1 \%$ level in asthmatics and $0.1 \%$ level in bronchitics. The difference was also highly significant $(P \ll 0.001)$ for F.V.C. and P.F.R. in the groups as a whole. In asthmatics improvement in F.E.V., following Bronchilator was recorded at five minutes, reaching a maximum at $30-45$

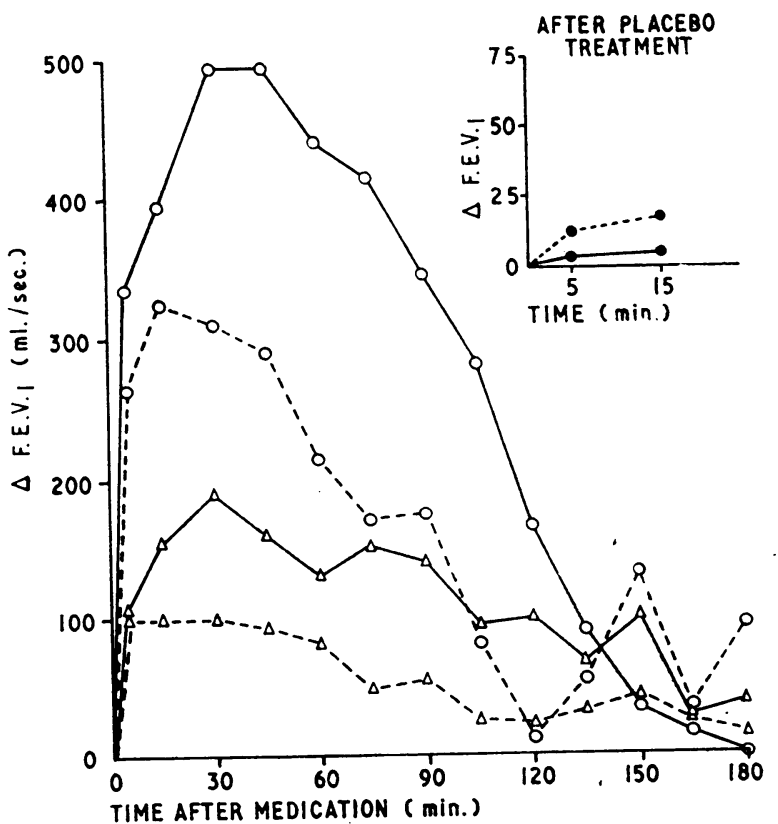

FIG. 1.-Mean improvements in F.E.V. in asthmatics $(O)$ and bronchitics $(\triangle)$. Plotted are mean differences, F.E.V. (=F.E.V..1 at time $t$ after medication-F.E.V. immediately prior to medication) against t. Isoprenaline: - .-, 10 asthmatics, 11 bronchitics. Bronchilator:

prenaline: --, 15 minutes after placebo (asthmatics and bronchitics combined). 
minutes, and was still significant at 105 minutes ( $5 \%$ level). In bronchitics significant improvement occurred up to 90 minutes. After isoprenaline, improvement in F.E.V., was also recorded at five minutes, reaching a maximum at 15 minutes, and was still significant at 90 minutes ( $5 \%$ level). In bronchitics the improvement remained significant up to 60 minutes.

\section{Pulse and Blood-pressure}

Part 1.-The results in the first session were analysed. Significant reduction $(0.1 \%$ level $)$ of pulse rate occurred after

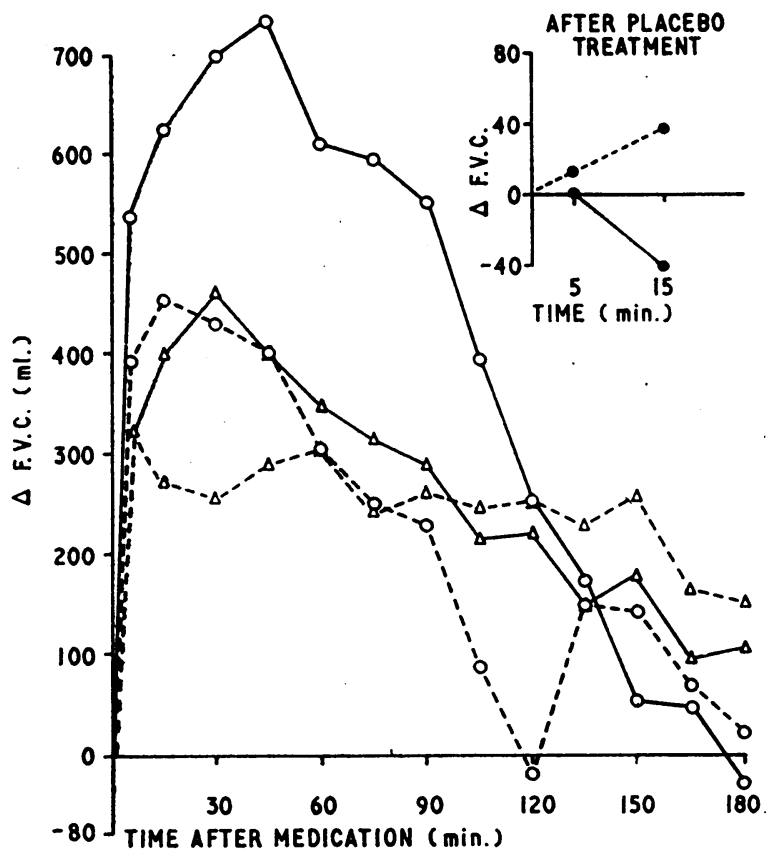

FIG. 2.-Mean changes from premedication control levels in F.V.C. for bronchitics $(\triangle)$ and asthmatics $(O)$ in both groups of patients. Plotted are mean differences, F.V.C. $(=$ F.V.C. at time $t$ after medication - F.V.C are mean differences, F.V.C. (=F.V.C. at time $t$ after medication -F.V.C. immediately prior to medication) against t. Isoprenaline : - - 10,10
asthmatics, 11 bronchitics. Bronchilator : bronchitics. Inset: Mean changes from control level 5 and 15 minutes after taking placebo (asthmatics and bronchitics combined).

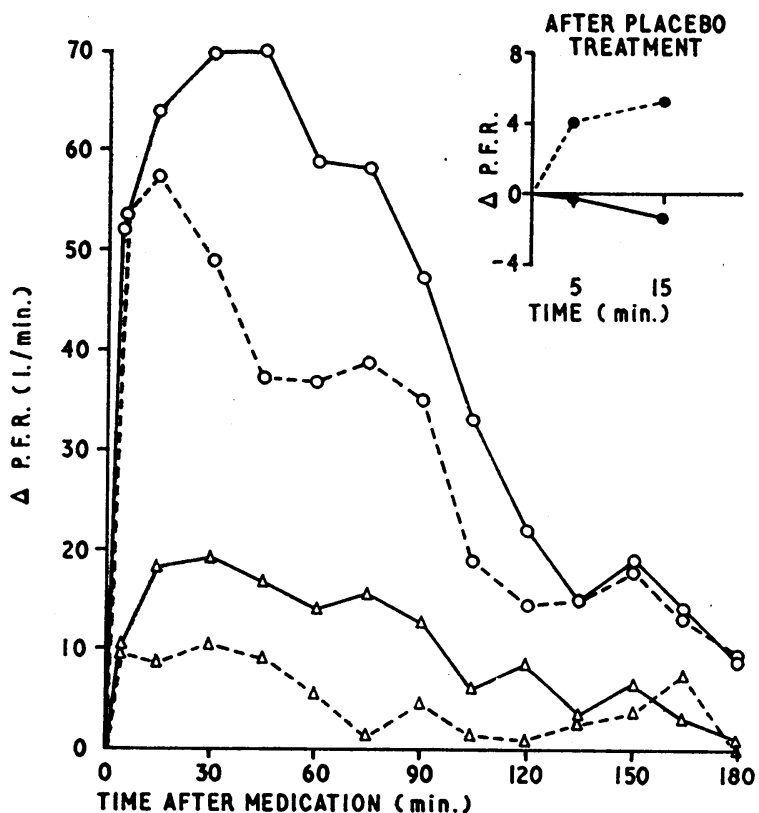

FIG. 3.- Mean changes from premedication control levels in P.F.R. for bronchitics $(\triangle)$ and asthmatics $(O)$ in both groups of patients. Plotted are mean differences, P.F.R. (= P.F.R. at time $t$ after medication-P.F.R. immediately prior to medication) against t. Isoprenaline: - P.F.R. asthmatics, 8 bronchitics. Bronchilator: - 13 asthmatics, 8 bconchitics. Inset: Mean changes from control level 5 and 15 minutes after taking placebo (asthmatics and bronchitics combined).
Bronchilator as well as after the placebo, but there was no significant change after isoprenaline. Both active drugs were followed by significant reduction $(0.1 \%$ level $)$ in blood-pressure, but no change was apparent after the placebo.

Part II.-Fig. 4 shows the mean change in pulse rate following treatments with both active drugs for a period of three hours. An immediate increase in pulse rate is apparent after isoprenaline, followed in 15 minutes by a decrease to a level fluctuating around the baseline. Slowing of pulse rate occurred after Bronchilator and placebo. Fig. 5 shows diagrammatically the mean changes in diastolic, systolic, and pulse pressures at 13 time intervals in both groups. The maximum mean reduction in pressures (systolic $18.3 \mathrm{~mm}$., diastolic $6.9 \mathrm{~mm}$. $\mathrm{Hg}$ ) occurred at 15 minutes in the isoprenaline group, whereas in the Bronchilator group the maximum reductions (systolic $6.4 \mathrm{~mm}$., diastolic $2.8 \mathrm{~mm}$. $\mathrm{Hg}$ ) occurred at 45 minutes. It can be seen

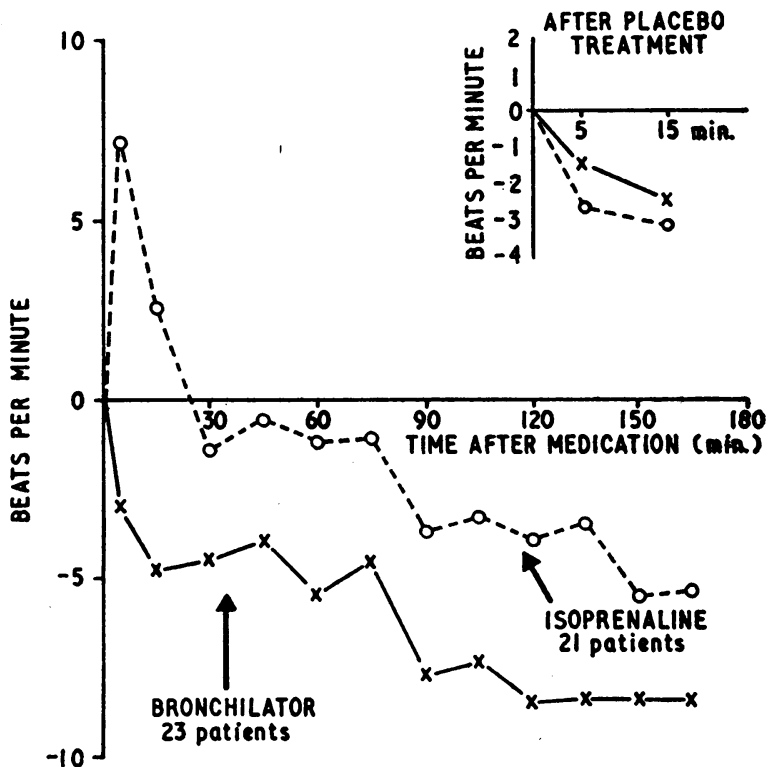

FIG. 4.-Mean pulse-rate changes in isoprenaline and bronchilator groups. Plotted are mean differences: pulse rate at time $t$ after medication-pulse rate immediately prior to medication, against $t$.

\section{MINUTES AFTER MEDICATION}

$\begin{array}{lllllllllllll}5 & 15 & 30 & 45 & 60 & 75 & 90 & 105 & 120 & 135 & 150 & 165 & 180\end{array}$

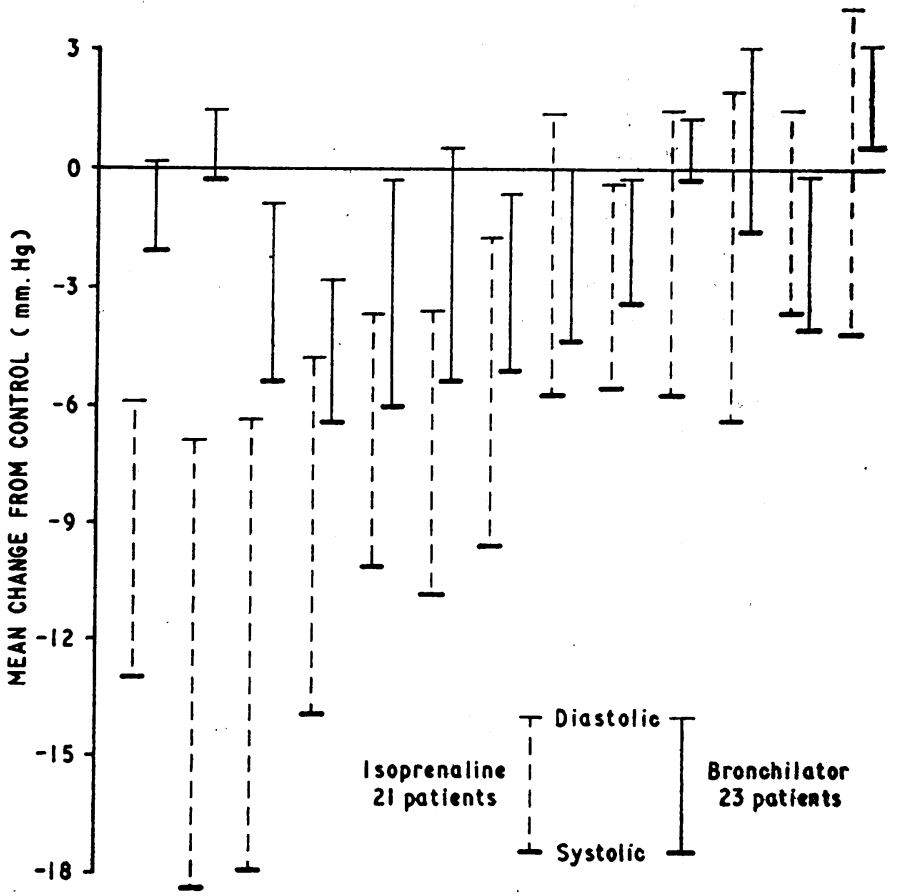

Fig. 5.-Mean blood-pressure changes from control levels. 
that reductions in pressures in the isoprenaline group are consistently greater than those in the Bronchilator group for at least 90 minutes. The difference between the two groups was highly significant for systolic and diastolic reductions $(P \ll 0.001$ and $<0.01$ respectively). In the isoprenaline group highly significant reductions in systolic and diastolic bloodpressures occurred ( $P \ll 0.001$ and $<0.01$ respectively). For systolic pressure the reductions were significant at $0.1 \%$ level up to 30 minutes, at $1 \%$ level up to 75 minutes, and at $5 \%$ level up to 90 minutes. For diastolic pressure the reductions were significant at $1 \%$ level up to 30 minutes and at $5 \%$ level at 45 minutes. In the Bronchilator group reductions in systolic pressure were significant $(P \ll 0.001)$, reaching $2 \%$ level at 45 minutes. For diastolic pressure the changes were not significant at the $5 \%$ level.

\section{Side-effects}

One woman felt faint after placebo and Bronchilator treatment in Part I and 120 minutes after isoprenaline inhalations in Part II. No other side-effects were noted in the group.

\section{Discussion}

It is appreciated that in patients with obstructive airway disease lung-function tests give varying results throughout the 24 hours, the lowest levels occurring early in the morning (Lewinsohn et al., 1960). Difficulties also arise when an attempt is made to compare drug treatments in asthma, owing to the variations in response between patients and in the same patient at different times (Hume and Gandevia, 1957). Also interpretation of lung-function tests is limited unless patients' full co-operation is achieved. These factors were taken into consideration when this trial was designed and every attempt was made to minimize their influence.

It is accepted that asthmatics have reversible obstructive airway disease, whereas in bronchitics the functional obstruction is only partially reversible. In Part I, patients differed significantly in the extent of improvement shown by lung-function tests after treatment. In addition to the expected variation between patients in response to therapy, the difference in the magnitude of improvement between asthmatics and bronchitics could also partly account for this finding.

Although the curves plotted in Figs. 1, 2, and 3 from the data obtained in Part II show the superiority of Bronchilator over isoprenaline for at least two hours, these curves only show the mean improvement differences in lung-function tests and do not reflect the wide differences between patients' response to either drug. Analysis of linear regression for data from 30 to 180 minutes after medication confirmed that the observed differences between Bronchilator and isoprenaline were real and not merely the result of random fluctuation or variation between patients.

The curves for F.E.V., F.V.C., and P.F.R. are similar for both active drugs. This similarity suggests that those measurable improvements in P.F.R. are closely related to corresponding improvements in F.E.V. ${ }_{1}$ and F.V.C. A close correlation between P.F.R. and maximum voluntary ventilation was reported (Higgins, 1957 ; Prime, 1960), but no such correlation was found between P.F.R. and F.E.V., measurements (Prime, 1960). Bouhuys (1957, 1960) felt that the P.F.R. was not sensitive as a measurement of ventilating capacity, and values obtained on successive observations on one patient were more variable than F.E.V., measurements. Study of the data in this trial suggested that the P.F R. was the least useful of the three lung-function tests ; on 136 occasions no records could be obtained.

Spielman (1961) and Goldfarb and Romanoff (1962) reported reductions in pulse rates following Bronchilator. In this con- trolled trial, reductions in pulse rate occurred after the placebo as well as after Bronchilator. After isoprenaline an immediate rise in pulse rate lasting for about 15 minutes was found. This was not evident in Part I, where pulse rates were taken 15 minutes after inhalations. The administration of a smaller dose might have also played a part.

Blood-pressure reductions after Bronchilator have been reported (Herschfus et al., 1951; Spielman, 1961). The former found no change in pulse pressure in five patients. Goldfarb and Romanoff (1962) claimed that large reductions in bloodpressures occurred after Bronchilator (systolic 20-30 mm., diastolic $10-20 \mathrm{~mm}$. $\mathrm{Hg}$ ), and they suggested that their findings warranted further study. In the present series reduction in systolic but not in diastolic blood-pressure was statistically significant ( $2 \%$ level) after Bronchilator. The mean maximum blood-pressure reductions, however, were small (systolic 6.4 mm., diastolic $2.8 \mathrm{~mm}$. $\mathrm{Hg}$ ), and were similar in extent in hypertensive and normotensive patients.

\section{Summary}

Lung-function tests in 35 asthmatics and 25 bronchitics were used in a double-blind controlled trial to compare the effect and duration of a new sympathomimetic aerosol-isoetharine (Bronchilator) with those of isoprenaline.

The differences between improvements in lung-function tests following both active drugs and the placebo were highly significant. The means of maximum improvements in lungfunction tests were much more pronounced in asthmatics than in bronchitics, and were greater after Bronchilator than after isoprenaline. Maximum improvement in F.E.V. $\cdot$ occurred 30 to 45 minutes after Bronchilator and the effect was still significant at 105 minutes. For isoprenaline, maximum improvement occurred at 15 minutes and the effect was still significant at 90 minutes. The improvement shown in lung-function tests after Bronchilator was greater than that following isoprenaline for at least two hours. The observed difference in improvements between the two drugs was real and not due to random fluctuation or variation between patients.

A mean increase in pulse rate for 15 minutes followed isoprenaline. This was not demonstrated after Bronchilator. Reductions in blood-pressure occurred after both active drugs, and were consistently greater after isoprenaline for at least 90 minutes.

I am indebted to Dr. D. A. Williams for advice and facilities offered at the Asthma and Allergy Research Unit; to Dr. A. J. Thomas for encouragement; to Dr. J. Picton Thomas for reading this paper; to Mr. M. Robertson, chief technician, for measurements of lung-function tests; to Dr. G. B. Hill fór programming the computer, to $\mathrm{Mr}$. M. Jacobsen for statistical analyses; to $\mathrm{Mr}$. S. D. Jones, of Bayer Products Company, for supply of aerosols; and to members of the Medical Records Department of St. David's Hospital for their co-operation.

\section{REFERENCES}

Bouhuys, A. (1957). Acta med. scand., 159, 91.

(1960). Brit. med. F., 1, 1209.

Goldfarb, A. A., and Romanoff, A. (1962). Ann. Allergy, 20, 307.

Herschfus, J. A., Bresnick, E., Levinson, L., and Segal, M. S. (1951). Ibid., 9, 769.

Higgins, I. T. T. (1957). Brit. med. F., 2, 1198.

Hume, K. M., and Gandevia, B. (1957). Thorax, 12, 276.

Hume, K. M.' (1962). Arch. int. Pharmacodyn., 138, 462.
Lands, A. pharm. Ass., Sci. Ed., 47, 744.

Lewinsohn, H. C., Capel, L. H., and Smart, J. (1960). Brit. med. F., 1, 462.

McKerrow, C. B., McDermott, M., and Gilson, J. C. (1960). Lancet, 1, 149.

Prime, F. J. (1960). Brit. med. 7., 1, 423.

Scadding, J. G. (1963). Ibid., 2, 1425.

Siegel, C. (1962). 7.-Lancet, 82, 461.

Siegel, C. (1962). (1961). Curr. ther. Res., 3, 235.

Williams, D. A. (1961). Acta allerg. (Kb̆h.), 16, 400.

Wright, B. M., and McKerrow, C. B. (1959). Brit. med. F., 2, 1041. 